\title{
GENOTYPE $\times$ ENVIRONMENT INTERACTION IN CHICKPEA (Cicer arietinum L.) UNDER AFGHANISTAN ENVIRONMENTS AND IDENTIFICATION OF HIGH YIELDING GENOTYPES
}

\author{
Lina Mohammadi ${ }^{1}$, Yashpal Saharawat ${ }^{1},{ }^{*}$, Darya Khan Akbarzai ${ }^{1}$, Abdul Rahman Manan ${ }^{1}$, \\ Assadullah Habibi ${ }^{1}$, Qudratullah Soofizada ${ }^{2}$, Srinivas Tavva ${ }^{1}$, \\ Nigamananda Swain ${ }^{1}$, Murari Singh ${ }^{3}$
}

\footnotetext{
${ }^{1}$ International Center for Agricultural Research in the Dry Areas (ICARDA), Kabul, Afghanistan

${ }^{2}$ Ministry of Agriculture, Irrigation and Livestock (MAIL), Kabul, Afghanistan

${ }^{3}$ International Center for Agricultural Research in the Dry Areas (ICARDA), Amman, Jordan

Received - April 17, 2017; Revision - June 06, 2017; Accepted - August 26, 2017

Available Online - September 10, 2017
}

DOI: http://dx.doi.org/10.18006/2017.5(4).428.438

KEYWORDS
Chickpea
Genotypes $\times$ environment
interaction
Adaptation
Afghanistan
GGE bi-plot

* Corresponding author

E-mail: y.saharawat@cgiar.org (Yashpal Saharawat)

Peer review under responsibility of Journal of Experimental Biology and Agricultural Sciences.

Production and Hosting by Horizon Publisher India [HPI] (http://www.horizonpublisherindia.in/).

All rights reserved.

\begin{abstract}
To meet the growing demand of food and protein of Afghan population, winter-sown chickpea (Cicer arietinum L.) is an important contributor but its productivity needs to be increased. Therefore this study was conducted to identify high yielding and disease resistant genotypes suitable for winter-sowing in Afghanistan. Three field trials denoted as CIEN-W (Chickpea International Elite Nursery - wintersown), CIABN (Chickpea International Ascochyta Blight Nursery) and CIFWN (Chickpea International Fusarium Wilt Nursery) were conducted in block designs with replications at a total of four diverse locations Baghlan, Herat, Kabul, and Nangarhar during 2014-15 and 2015-16 seasons. Genotypes considered in this study were from a series of previously conducted trials by ICARDA Chickpea Improvement Program. Genotypic differences were statistically significant in 10 of the 14 individual trails and genotype $\times$ location interactions were significant for CIEN-W (both years) and CIABN and CIFWN for 2015. The high yielding genotypes identified from CIEN-W materials were ILC482 adapted in Kabul (both years) and Baghlan (2015), FLIP 09-131C in 2015 and FLIP 88-85C in 2016 at Nangarhar and FLIP 09-441C in 2016 in Baghlan. In Herat, FLIP 09-276C from CIABN trial and FLIP
\end{abstract}

All the article published by Journal of Experimental Biology and Agricultural Sciences is licensed under a Creative Commons Attribution-NonCommercial 4.0 International License Based on a work at www.jebas.org. 
09-206C in Herat from the CIFWN trials were the top yielders in 2015. The genotypes that yielded highest in all the climatic conditions and the geographical regions were FLIP 88-85 C $\left(1.77 \mathrm{t} \mathrm{ha}^{-1}\right)$ in CIEN-W), FLIP 09-414 C (1.11 $\left.\mathrm{tha}^{-1}\right)$ in CIABN) and FLIP-09-420C $\left(1.18 \mathrm{t} \mathrm{ha}^{-1}\right)$ in CIFW. These genotypes are recommended in crossing program for genetic enhancement and chickpea production to support food security in Afghanistan.

\section{Introduction}

Chickpea (Cicer arietinum L.) is the world's third ranking food legume, and is grown on about 11.5 million hectares; $96 \%$ of all production takes place in developing countries. Chickpea production has increased over the past 30 years from 6.5 million tons (1978-1980 average) to 9.6 million tons (2007-09) (ICRISAT - http://exploreit.icrisat.org/profile/Chickpea/232). The highest producing countries are India (8.832 million tons), Australia (8.813 million tons) and Pakistan ( 0.751 million tons) in 2013 (FAO, 2014). In Afghanistan, around 115000 hectares of land is cultivated under pulses and chickpea production contributes about $18.17 \%$ of total pulses production (MAIL, 2014). Further, chickpea is a major legume crop grown predominantly in northeast and central provinces including Takhar, Kunduz, Herat, Badakhshan, Mazar-e-Sharif, Samangan, Bamyan, Baghlan, Kapisa, Wardak, Ghazni and Zabol provinces, normally under irrigation systems (USDA - http://afghanag.ucdavis.edu/b_fieldcrops/chickpea). Two major types of chickpea viz. Kabuli, a lighter-colored large seed, and desi, which is smaller and darker with a rough coat are cultivated in Afghanistan. At present, the productivity of food legumes is less than $1.0 \mathrm{t} \mathrm{ha}^{-1}\left(0.75 \mathrm{tha}^{-1}\right)$ and the current production $(60,000 \mathrm{t})$ does not meet the demand of growing Afghanistan population (FAOSTAT, 2016). The main factors are non-availability of quality seed of chickpea variety associated with high yields, poorly adopted improved varieties and the associated management practices (ICARDA IFFVC Baseline Report, 2014). To meet the protein requirement of growing population of Afghanistan, high productive and widely and specifically adapted chickpeas genotypes are needed for rainfed and irrigated systems. For increasing chickpea production in the country, the high yielding winter type genotypes are required to fill the current yield gap. Tavva et al. (2017) estimated that chickpea yield gap due to technological factors such as improved variety and production package at the level of $73 \%$ based on on-farm trials data from six districts in two provinces $(2009-12)$.

Genotype-environment interaction (GEI) plays an important role in identification of the genotypes in response to the environment. GEI an important source of phenotypic variation is of great importance in the development and evolution of plant cultivars. A wide range of techniques and tools for estimation and exploitation of GEI have been described in literature (Kemptorne, 1952; Finlay \& Wilkinson, 1963; Eberhart \& Russell, 1966; Lin et al., 1986; Gauch \& Zobel, 1988; Delacy et al., 1996a; Delacy et al., 1996 b). As the phenotypes are under the control of genes, the breeders are able to select suitable genotypes in advanced generations by growing them under different environmental conditions (Pervin et al., 2007). Yield trials have to be conducted in multiple environments to measure $\mathrm{G} \times \mathrm{E}$ interactions, quantify and identify any patterns in it. The presence of significant genotype by environment interaction in chickpea has been reported by various authors (Singh et al., 1990; Bozoglu \& Gulumser, 2000). GEI in chickpea with environments being site, years and sowing-seasons have been exploited for identifying varieties for a specific sowing season and dual season purposes in Mediterranean environments (Malhotra et al., 2007; Imtiaz et al., 2013). Graphical tools for identification of mega-environments and specifically adapted genotypes are presented in Yan et al., (2000) and Yan (2011). In neighboring Iranian environments, an analysis of genotype by environment data was carried out to examine the nature of genotype by environmental interaction in chickpea by Farshadfar et al., (2011). While several studies to evaluate GEI in chickpea have been reported for environments in many countries (Bakhsh et al., 2011;Singh et al., 1990; Bozoglu \& Gulumser, 2000; Farshadfar et al., 2011; Imtiaz et al., 2013; Tilahun et al., 2015), but such an evaluation is not available for chickpea growing environments in Afghanistan.

International Center for Agricultural Research in the Dry Areas (ICARDA) - Afghanistan Program has been conducting field evaluations of chickpea genetic material for winter sowing with a on high yielding, cold tolerance, Ascochyta blight resistance, Fusarium wilt tolerance, large seed size and for spring sowing with a focus on high yielding, drought and Fusarium wilt tolerance, large seed size. Each of the three types of genetic materials --Chickpea International Elite Nursery - winter-sown (CIEN-W), Chickpea International Ascochyta Blight Nursery $(\mathrm{CIABN})$ and Chickpea International Fusarium Wilt Nursery (CIFWN) - were evaluated in multi-environment trials with the objectives (i) to examine genotypic variation in winter season chickpea, (ii) to detect the genotypes $\times$ environment interaction and (iii) to identify specifically and widely adapted genotypes with high yield. 


\section{Materials and Methods}

\subsection{Experimental site and Material}

Total 118 chickpea genotypes were tested in three trials during 2014-15 and out of which 55 genotypes were tested in 2015-16 during the winter season at a total of four locations i.e. Baghlan (36 $052903 \mathrm{~N}, 68^{\circ} 384944 \mathrm{E}, 599 \mathrm{~m}$ asl, average annual precipitation $190.51 \mathrm{~mm})$, Herat $\left(39^{\circ} 11 \mathrm{~N}, 68^{\circ} 131 \mathrm{E}, 964 \mathrm{~m}\right.$ asl, average annual precipitation $205 \mathrm{~mm}$ ), Kabul (at $34^{\circ} 27 \mathrm{~N}, 69^{\circ} 7$ E, $1836 \mathrm{~m}$ asl, average annual precipitation $321 \mathrm{~mm}$ ), and Nangarhar $\left(34^{\circ} 25 \mathrm{~N}, 70^{\circ} 27 \mathrm{E}, 552 \mathrm{~m}\right.$ asl, average annual precipitation $225.5 \mathrm{~mm}$ ) (Fig. 1). The three trials were: Chickpea International Elite Nursery - winter (CIEN-W) conducted at the experimental locations in Baghlan, Kabul and Nangarhar provinces; Chickpea International Ascochyta Blight Nursery (CIABN) and Chickpea International Fusarium Wilt Nursery (CIFWN), both were conducted at the locations in Heart and Kabul provinces.

\subsection{Experimental Design}

During 2014-15, CIEN-W trial comprised 36 chickpea genotypes evaluated in simple lattice design at three locations, and the other two trials CIABN and CIFWN were conducted with 41 genotypes in randomized complete block designs (RCBD) with two replicates. All the three trials were conducted in RCBDs during 2015-16 with 15 genotypes (CIEN-W) and 20 (CIABN and CIFWN) with three replicates (Table 1). The number of genotypes common between the two years of trial were 14 for CIEN-W and 19 for CIABN and CIFWN. The plot sizes were 3.6 $\mathrm{m}^{2}$ with $0.45 \mathrm{~m}$ row to row distance, $4 \mathrm{~m}$ row length and 2 rows per plot in 2014-15, and $6.4 \mathrm{~m}^{2}$ with two 4 rows, each $4 \mathrm{~m}$ long and $40 \mathrm{~cm}$ row to row distance in $2015-16$, for all trials. Grain yield obtained from the $3.15 \mathrm{~m}^{2}$ area for all trials in 2014-15 and $2.4 \mathrm{~m}^{2}$ area in 2015-16, was converted to ton per hectare for statistical analysis.

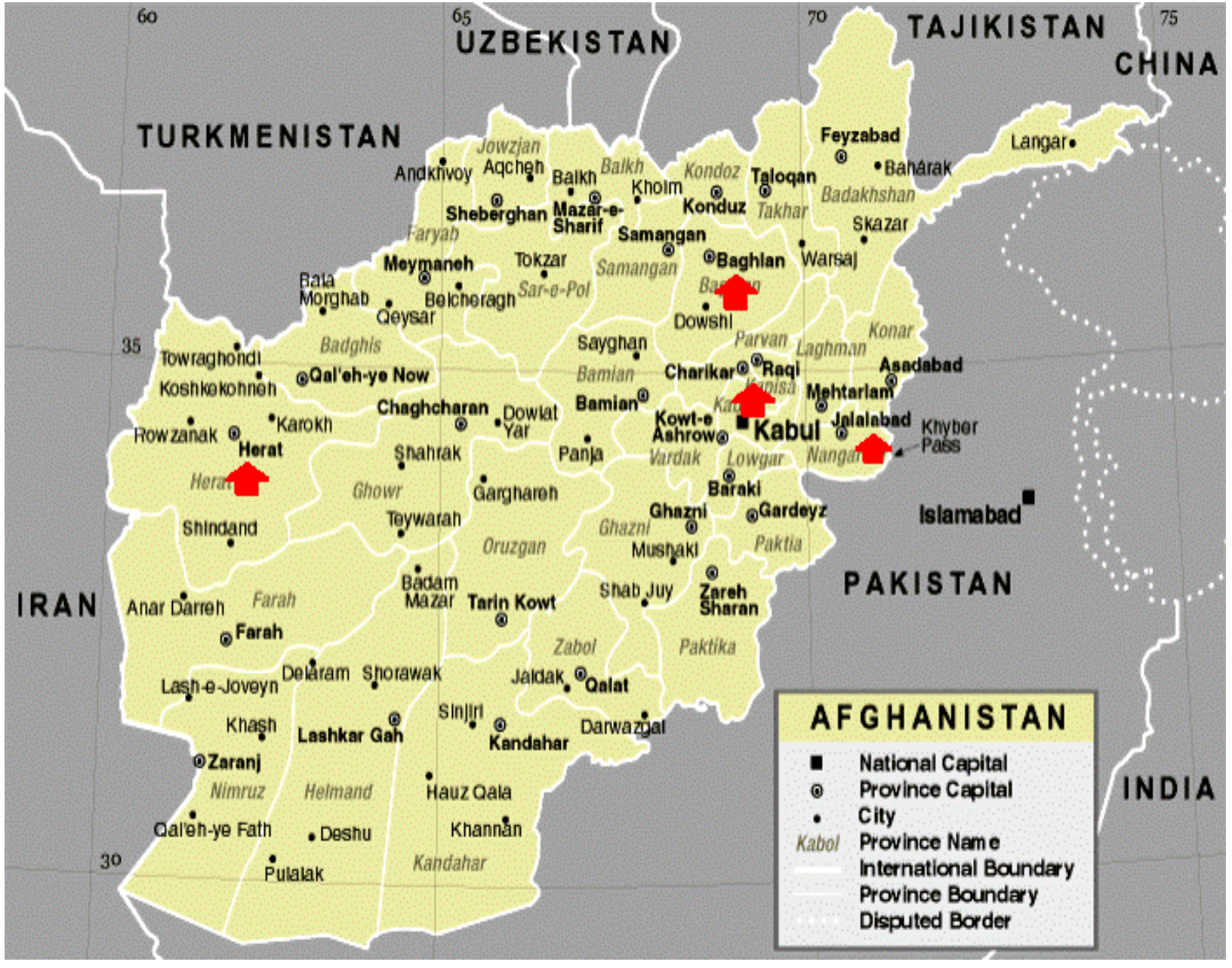

Figure 1 A map with arrows showing the trial locations in Afghanistan

Journal of Experimental Biology and Agriculture Science http://www.jebas.org 


\subsection{Statistical analysis}

The data set from a given location and year was analyzed by fitting the mixed model where block effects were assumed random where lattice designs was used, and the analysis of variance (ANOVA) model was used for RCBDs. Our interest was in evaluating and comparing specific genotypes, their effects were assumed as fixed. For each trial type, the analysis was carried out on combined data over all the locations each year and also combined over the years as well. The combined analyses provided information on genotype $\times$ location interaction (GLI) and genotype $\times$ year interaction (GYI) within locations. Since the locations represent diverse environments, their effects as well as GLI were assumed fixed. When combining the data over the years, the year effects and GYI within locations were assumed random. Furthermore, the datasets combined over years were based on common genotypes and in RCBDs (i.e. for CIEN-W we ignored incomplete blocks only when combining over the two years). In order to describe further insight of the statistical analysis model used, let Yield, Rep, Blk, Geno, Loc and Year represent vectors containing plot-wise values for the yield (response), replicates, blocks within replicates, genotypes, locations and years respectively. These models were fitted by the REML (restricted maximum likelihood) directive in GenStat software (VSN Inc. 2015) using VCOMPONENTS directive of the Genstat software as in the following.

Data from a single simple lattice design (i.e. a given location and year combination):

VCOMPONENTS [Fixed=Geno] Rep + Rep.Blk ; constraints=positive

Data from simple lattices combined over locations for a given year:

VCOMPONENTS [Fixed=Geno+ Loc + Geno. Loc] Loc.Rep + Loc.Rep.Blk ; constraints=positive

Data from RCBDs combined over locations for a given year:

VCOMPONENTS [Fixed=Geno+ Loc + Geno. Loc $]$ Loc.Rep ; constraints=positive

Data from RCBDs combined over locations and years:

VCOMPONENTS [Fixed=Geno+ Loc + Geno. Loc] Year.Loc + Geno.Year.Loc+ Year.Loc.Rep; constraints=positive
Specific adaptation of genotypes to location was assessed using its GGE bi-plot (Yan 2011). Genotype plus genotype $\times$ environment interaction (GGE) bi-plots are graphical presentation of genotypes and environments, and compared environments for their genotypic differentiation, formation mega-environments and identifying genotypes adapted specifically to an environment. GGE bi-plots are obtained from an approximation of a GGE matrix into sum of products of vectors and displaying them on an often two dimension plot where genotypes are represented by points and environments by vectors. A polygon is drawn connecting the exterior most points (genotypes), and from the center perpendiculars are drawn on the polygon sides. The set of environments enclosed in the region formed by the perpendiculars on the neighboring sides is taken as a mega-environment. All the calculations including GGE bi-plots were carried out in GenStat software environment (VSN Inc., 2015).

\section{Results and Discussion}

\subsection{Genotypic variability at individual environments}

For each location of the trials, Table 1 presents field level experimental information in terms of mean and filed heterogeneity measured by the plot-error coefficient of variation (CV). The statistical significance of genotypic effect has been given as Pvalue, the probability of observing large value of the test statistics or extreme data when the genotype effect is absent. Genotypic differences at the individual environments (location - year combination) were found statistically significant ( $\mathrm{P}<0.024)$, except for CIABN in 2016 (both locations), 2015 (Kabul) and CIFWN in 2016 in Herat. The overall mean at an environment varies from $0.98-2.33 \mathrm{t} \mathrm{ha}^{-1}$ for CIEN-W, 0.21-1.66 $\mathrm{t} \mathrm{ha}^{-1}$ for CIABN and $0.16-1.56 \mathrm{t} \mathrm{ha}^{-1}$ for CIFWN. The CV varied from 21- 29\% in CIEN-W trials and was found in unusually high range $12-63 \%$ for CIABN and $14-78 \%$ for CIFWN. The environments where the $\mathrm{CV}$ was very high, the mean yield was very low, $0.16-$ $0.21 \mathrm{t} \mathrm{ha}^{-1}$, and the genotypic differences were not significant ( $\mathrm{P}$ in $0.57-0.94$ ). This could be due to the effects of multiple uncontrolled factors including field heterogeneity, germination affected by the local environment and damages caused by birds and small ruminants which resulted into a few missing plots. During 2016, there were eight missing plots in CIABN and two in CIFWN trial. Mukamuhirwa et al. (2015) reported some missing plots in his study and Negash (2015) described that missing data usually occurred in multi-environments due to adverse weather conditions, dead or damaged plants, incorrect data measurement or transcription and that missing data posed problems in using various analysis methods. 
Table 1 Trial name, location, number of genotypes, experimental design, location mean grain yield, coefficient of variation (CV), and significance (P-value) for genotypic effect

\begin{tabular}{|c|c|c|c|c|c|c|c|}
\hline Trial name $\dagger$ & Year & $\begin{array}{l}\text { Location } \\
\text { Name }\end{array}$ & Experimental design & No of genotypes & overall mean & $\mathrm{CV}(\%)$ & P-Value \\
\hline \multirow[t]{6}{*}{ CIEN-W } & \multirow[t]{3}{*}{$2014-15$} & Baghlan & Simple lattice & 36 & 1.66 & 18.5 & 0.020 \\
\hline & & Kabul & Simple lattice & 36 & 1.80 & 27.7 & 0.001 \\
\hline & & Nangarhar & Simple lattice & 36 & 1.07 & 29.1 & 0.000 \\
\hline & \multirow[t]{3}{*}{ 2015-16 } & Baghlan & RCBD & 15 & 2.33 & 22.8 & 0.006 \\
\hline & & Kabul & RCBD & 15 & 0.93 & 31.3 & 0.000 \\
\hline & & Nangarhar & RCBD & 15 & 0.98 & 20.6 & 0.001 \\
\hline \multirow[t]{4}{*}{ CIABN } & \multirow[t]{2}{*}{$2014-15$} & Kabul & RCBD & 41 & 0.25 & 32.2 & 0.088 \\
\hline & & Herat & RCBD & 41 & 1.37 & 11.5 & 0.000 \\
\hline & \multirow[t]{2}{*}{$2015-16$} & Kabul & RCBD & 20 & 0.21 & 62.9 & 0.497 \\
\hline & & Herat & RCBD & 20 & 1.66 & 25.4 & 0.576 \\
\hline \multirow[t]{4}{*}{ CIFWN } & \multirow[t]{2}{*}{$2014-15$} & Kabul & RCBD & 41 & 0.56 & 23.2 & 0.024 \\
\hline & & Herat & RCBD & 41 & 1.45 & 13.9 & 0.000 \\
\hline & \multirow[t]{2}{*}{ 2015-16 } & Kabul & RCBD & 20 & 0.16 & 77.8 & 0.011 \\
\hline & & Herat & RCBD & 20 & 1.56 & 22.2 & 0.944 \\
\hline
\end{tabular}

${ }^{\dagger} \mathrm{CIEN}-\mathrm{W}=$ Chickpea International Elite Nursery - Winter. CIABN = Chickpea International Ascochyta Blight Nursery. CIFWN = Chickpea International Fusarium Wilt Nursery. CV= coefficient of variation. P-value = Probability of observing the extreme data in the absence of genotypes effects

\subsection{Genotype $\times$ environment interaction}

Table 2 presents results on genotype $\times$ location interaction (GLI) for each year and genotype $\times$ year interaction within locations (GYIwL) in terms of significance and estimates of variance components. Year wise data analysis showed that genotype $\times$ location interactions $(\mathrm{GLI})$ were significant $(\mathrm{P}<0.01)$ in all the trials except for CIABN and CIFWN in 2016 (Table 2A). For the cases with significant GLI, the genotypic variation $(G)$ averaged over locations were also found significant $(\mathrm{P}<0.01)$. When the data was combined over the locations and the years, genotype $\times$ year interaction within locations (GYIwL) was found significant $(\mathrm{P}<0.01)$ for CIEN-W and CIFWN (Table 2B). The GLI and G were found insignificant in each of the trials. This is reflecting a strong crossover type effect due to the year in CIEN-W and, in addition, the high field heterogeneity ( $\mathrm{CV}$ values) that led to insignificant differentiation of genotypes in 2016 for CIABN and CIFWN (Table 1). Therefore, the specific adaptation to the locations was examined each year only for CIEN-W using GGE bi-plot procedure.
Variable patterns of GEI interactions have also been reported in chickpea by Nahar (1997) and Deb \& Khaleque (2004) in Bangladesh environments, that interaction between line and environment (GxE) was significant for all characters. Significant GxE interaction indicated that genotypic response varied with the environment. Season of planting being one of the environmental components was studied by Imtiaz et al. (2013) who reported that genotype $\times$ season interaction was more important than genotype $x$ location in Mediterranean environments. With the two distinct sowing times, the genotypes may respond to the photoperiods, temperatures, and rainfall regimes. However, the present study was confined to only one sowing season.

\subsection{Identification of specifically adapted and high yielding genotypes}

GGE bi-plots for CIEN-W trial are given in Figure 2 for 2015 and Figure 3 for 2016. The two dimensions of bi-plot representation explained $87 \%$ of the variation in GGE and results in formation of a mega-environments comprising Baghlan and Kabul locations 
Table 2 Significance of genotype, genotype $\times$ location interaction and error variance from year-wise combined data over locations and years, and genotype $\times$ year interaction within location

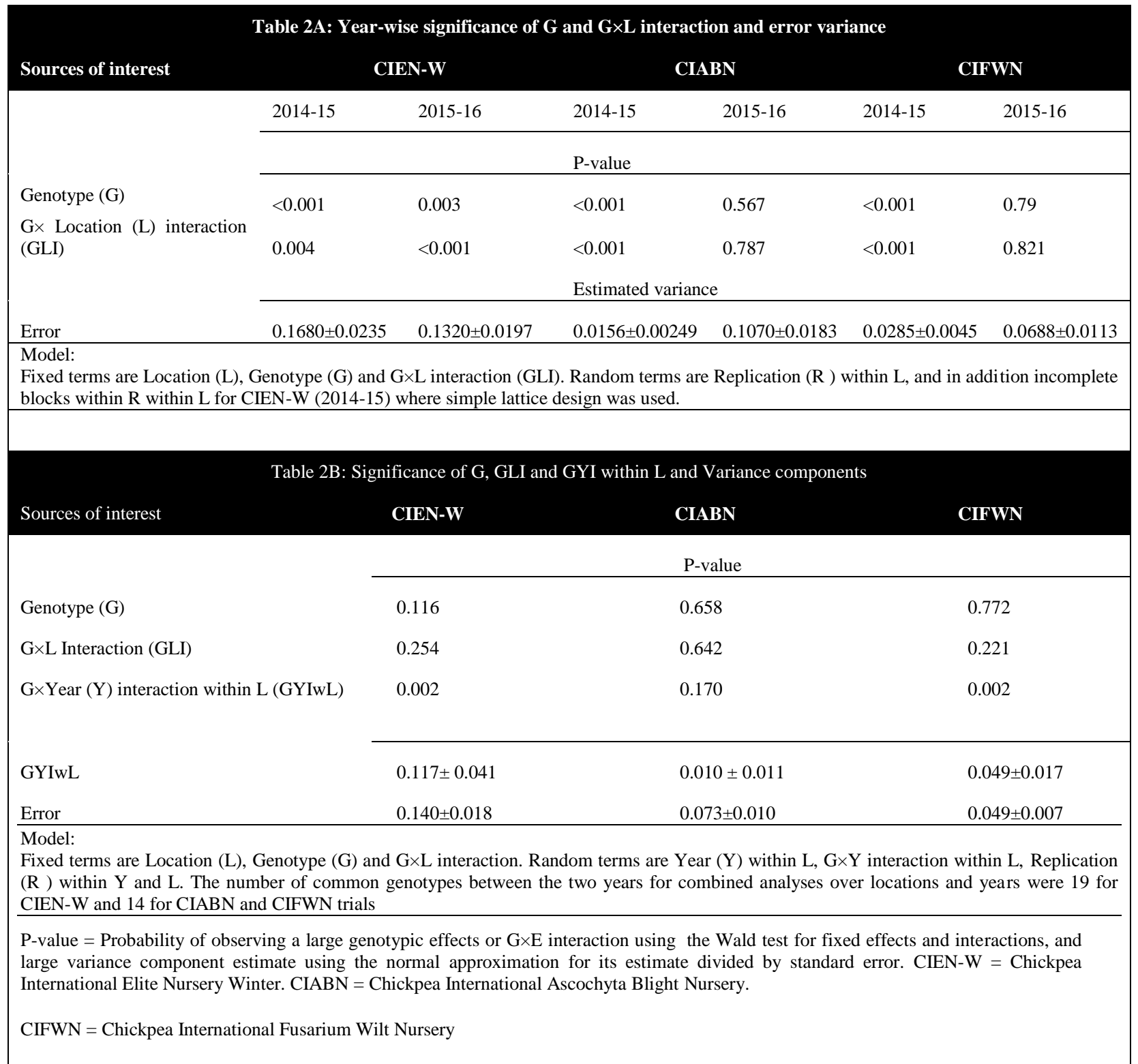

(Figure 2) while Nangarhar stands in separate sector. Kabul was found the most genotype discriminating location while Baghlan was the least. Thus in case rationalization of locations for chickpea evaluation is carried out, Kabul is preferred to Baghlan. Let the genotypes be coded as G1 to G36.The best grown genotype for the mega-environment (Baghlan and Kabul) was G32 (ILC482), at vertex of the polygon on the extreme right side along the first principal component axis, and is specifically adapted to Kabul. Genotype G3 (FLIP 09-131C) was specifically adapted to the Nangarhar environment. The representation of GGE based on 2016 data on 15 genotypes (G1...G15), not the same as of 2015, showed that the three locations represent different mega-environments (Figure 3). Baghlan was the most genotype-discriminating location, unlike that of Figure 2. This is due to strong interaction with year as supported by Table $2 \mathrm{~B}$. The winners for the environments represented by the locations Kabul, Nangarhar and Baghlan were G6 (ILC486), G8 (FLIP 88-85C) and G7 (FLIP 09-441C) respectively. In another legume, Atnaf et 
al. (2013) found that GGE biplots were effective for analyzing and visualizing the patterns of GEI in relation to test environment and genotypes of soybean.

Table 3 lists top ten genotypes with high mean (adjusted mean in case of simple lattice design) yields in each trial and each year where GEI was found statistically significant $(\mathrm{P}<0.01)$. The highest yielding genotypes in CIEN-W, 2015 were G32 (ILC482) at Baghlan (yield $2.1 \mathrm{t} \mathrm{ha}^{-1}$ ) and Kabul (3.29 $\mathrm{t} \mathrm{ha}^{-1}$ ) and G3 (FLIP 09-131C) at Nagarhar (1.71), and yielded $0.45 \mathrm{t} \mathrm{ha}^{-1}, 1.50 \mathrm{t} \mathrm{ha}^{-1}$ and 0.64 $\mathrm{tha}^{-1}$, respectively, more than the average yield of the location where found best for yield. In 2016, G6 (ILC482) repeated to be the highest yielding in Kabul while the genotypes found top yielding at the other two locations were G7(FLIP 09-141C) in Baghlan (yield $2.86 \mathrm{t} \mathrm{ha}^{-1}$ ) and G8 (FLIP 88-85C) in Nangarhar $\left(1.55 \mathrm{t} \mathrm{ha}^{-1}\right)$. Each of these genotypes yielded $0.5 \mathrm{t} \mathrm{ha}^{-1}$ over the average on the respective location. These genotypes also yielded the highest in the associated environments in the GGE bi-plots (Figures 2 and 3). Averaged over all the climatic and geographical conditions used in this study, best genotypes were FLIP 88-85 C (1.77 $\mathrm{t} \mathrm{ha}^{-1}$, CIEN-W), FLIP09-414 C (1.11 t ha- ${ }^{-1}$, CIABN) and FLIP-09420C (1.18 t ha ${ }^{-1}$, CIFWN). Atta \& Shah (2009) reported crossover type GEI in chickpea evaluated in Punjab province in Pakistan, which is consistent with the genotypes crossover interaction found with year in CIEN-W.

Since genotype effects and the interaction with location and year for CIABN and CIFWN trials were not significant for 2016, the best performing genotypes were identified on the basis of response in 2015. The top yielding genotypes for CIABN at Kabul was G41 (ILC263) with a yield of $0.47 \mathrm{t} \mathrm{ha}^{-1}$ $\left(0.22 \mathrm{t} \mathrm{ha}^{-1}\right.$ over the location mean) and C27 (FLIP 09-276C) in Herat (2.25 $\mathrm{t} \mathrm{ha}^{-1}$ which is $0.88 \mathrm{t} \mathrm{ha}^{-1}$ over the mean). In case of CIFWN, the highest yielding identified genotypes were G37 (FLIP 09418C) (yield $0.78 \mathrm{t} \mathrm{ha}^{-1}$ ) in Kabul and G26 (FLIP 09$206 \mathrm{C}$ ) (yield $2.45 \mathrm{t} \mathrm{ha}^{-1}$ ) in Herat with similar yield advantage as in the case of CIABN. Some other studies based on a single year data include those due to Kan et al. (2010) on the stable genotypes yielding higher than the general average, and Tilahun et al. (2015) for genotypic performance based on average across the locations involved.

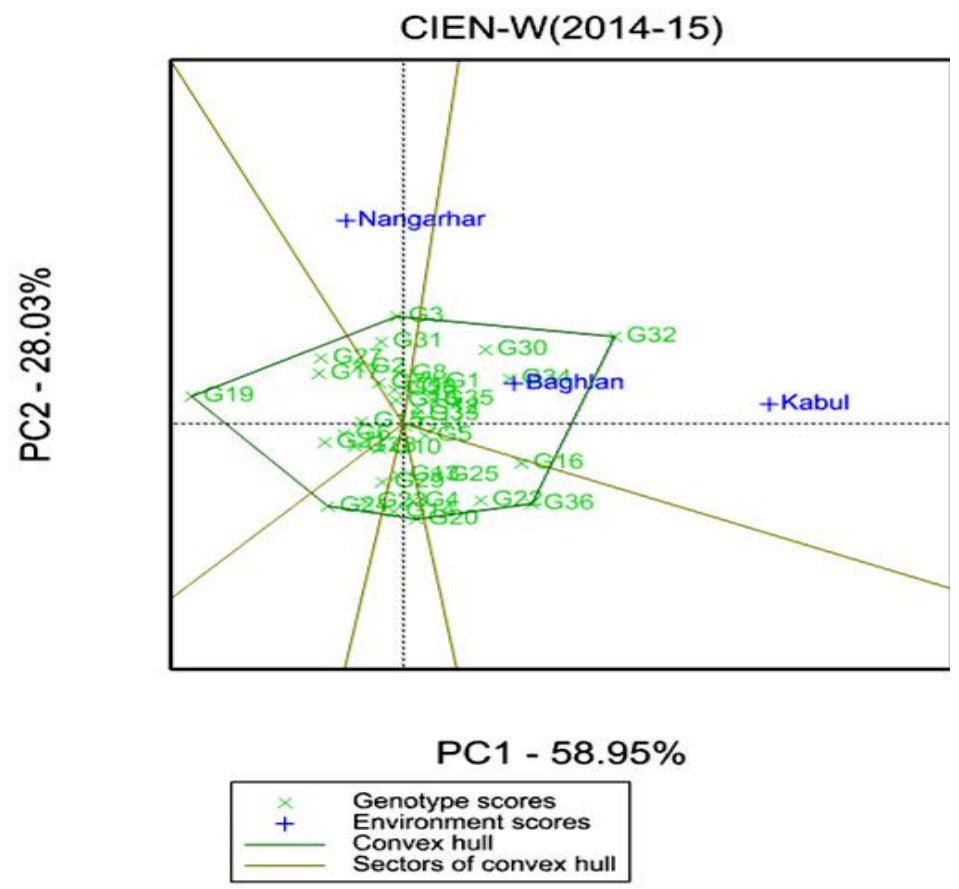

Figure 2 Genotype main effect plus genotype $\times$ environment interaction (GGE) biplot (scatter plot) for chickpea genotypes (G1...G36) and environments (Baghlan, Kabul, Nangarhar) for grain yield in 2015 under the trial CIEN-W

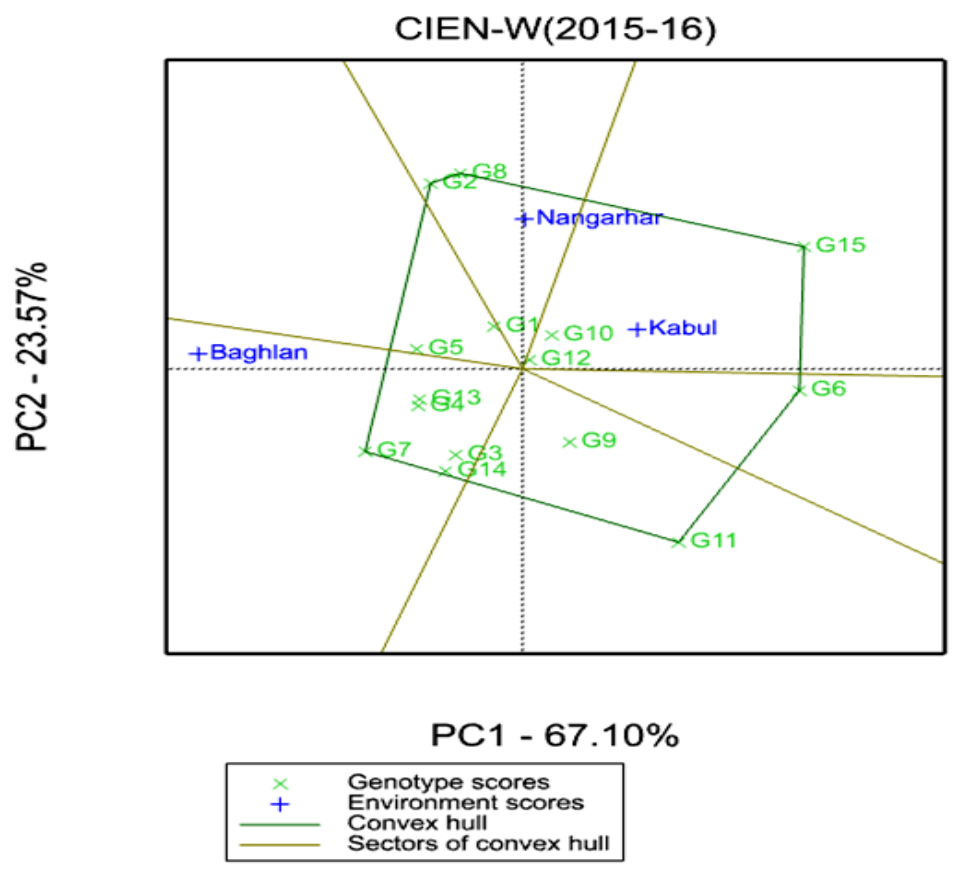

Figure 3 Genotype main effect plus genotype $\times$ environment interaction (GGE) biplot (scatter plot) for chickpea genotypes (G1 ...G15) and environments (Herat and Kabul) for grain yield in 2016 under the trial CIEN-W 
Table 3 Chickpea mean grain yields ( $t /$ ha) of top ten high yielding genotypes at specific locations in Afghanistan, $2014-2016$ for the three trials

\begin{tabular}{|c|c|c|c|c|c|c|c|c|c|}
\hline \multicolumn{10}{|c|}{ CIEN-W (2014-15) } \\
\hline Rank & GCode $^{@}$ & Genotype name & $\begin{array}{c}\text { Baghlan } \\
\left(\mathrm{t} \mathrm{ha}^{-1}\right)\end{array}$ & GCode & Genotype name & $\begin{array}{l}\text { Kabul } \\
\left(\mathrm{t} \mathrm{ha}^{-1}\right)\end{array}$ & GCode & $\begin{array}{c}\text { Genotype } \\
\text { name }\end{array}$ & $\begin{array}{c}\text { Nanga } \\
\text { rhar } \\
\left(\mathrm{tha}^{-1}\right)\end{array}$ \\
\hline 1 & G32 & ILC482 & 2.11 & G32 & ILC482 & 3.29 & G3 & FLIP 09-131C & 1.71 \\
\hline 2 & G27 & FLIP 09-396C & 2.02 & G36 & FLIP-92(LC) & 2.61 & G31 & FLIP 09-430C & 1.61 \\
\hline 3 & G26 & FLIP 09-387C & 2.01 & G16 & FLIP 09-441C & 2.60 & G19 & FLIP 09-305C & 1.54 \\
\hline 4 & $\mathrm{G} 24$ & FLIP 09-331C & 1.96 & G34 & FLIP $88-85 \mathrm{C}$ & 2.59 & G27 & FLIP 09-396C & 1.48 \\
\hline 5 & G11 & FLIP 09-239C & 1.94 & G30 & FLIP 09-423C & 2.47 & G30 & FLIP 09-423C & 1.47 \\
\hline 6 & G22 & FLIP 09-320C & 1.92 & $\mathrm{G} 22$ & FLIP 09-320C & 2.20 & G17 & FLIP 09-267C & 1.44 \\
\hline 7 & G3 & FLIP 09-131C & 1.91 & G1 & FLIP 07-189C & 2.05 & G2 & FLIP 09-53C & 1.43 \\
\hline 8 & G9 & FLIP 09-232C & 1.87 & $\mathrm{G} 25$ & FLIP 09-350C & 2.04 & G8 & FLIP 09-231C & 1.41 \\
\hline 9 & $\mathrm{G} 20$ & FLIP 09-318C & 1.82 & G35 & FLIP 93-93C & 1.99 & G32 & ILC482 & 1.39 \\
\hline \multirow[t]{4}{*}{10} & G36 & FLIP-92(LC) & 1.80 & G5 & FLIP 09-220C & 1.94 & G7 & FLIP 09-228C & 1.32 \\
\hline & SE & & 0.25 & & & 0.39 & & & 0.26 \\
\hline & LSD5\% & & 0.70 & & & 1.06 & & & 0.65 \\
\hline & Mean (36 genotypes) & & 1.64 & & & 1.79 & & & 1.07 \\
\hline \multicolumn{10}{|c|}{ CIEN-W (2015-16) } \\
\hline Rank & GCode & Genotype name & $\begin{array}{c}\text { Baghlan } \\
\left(\mathrm{t} \mathrm{ha}^{-1}\right)\end{array}$ & GCode & Genotype name & $\begin{array}{l}\text { Kabul } \\
\left(\mathrm{t} \mathrm{ha}^{-1}\right)\end{array}$ & GCode & $\begin{array}{c}\text { Genotype } \\
\text { name }\end{array}$ & $\begin{array}{l}\text { Nanga } \\
\text { rhar } \\
\left(\mathrm{t} \mathrm{ha}^{-1}\right)\end{array}$ \\
\hline 1 & G7 & FLIP 09-441C & 2.86 & G6 & ILC482 & 1.51 & G8 & FLIP $88-85 C$ & 1.55 \\
\hline 2 & G5 & FLIP 09-423C & 2.80 & G15 & Local check & 1.30 & $\mathrm{G} 2$ & FLIP 09-430C & 1.51 \\
\hline 3 & G13 & FLIP 09-440C & 2.79 & G12 & FLIP 09-387C & 1.23 & G15 & Local check & 1.36 \\
\hline 4 & G4 & FLIP 09-396C & 2.76 & G9 & FLIP 09-320C & 1.16 & G10 & FLIP 09-350C & 1.08 \\
\hline 5 & G2 & FLIP 09-430C & 2.72 & G1 & FLIP 09-131C & 1.14 & G1 & FLIP 09-131C & 1.01 \\
\hline 6 & G8 & FLIP $88-85 C$ & 2.59 & G5 & FLIP 09-423C & 1.03 & G5 & FLIP 09-423C & 0.93 \\
\hline 7 & G14 & FLIP 09-318C & 2.57 & G13 & FLIP 09-440C & 1.02 & G12 & FLIP 09-387C & 0.88 \\
\hline 8 & G1 & FLIP 09-131C & 2.51 & G11 & FLIP 09-331C & 0.96 & G6 & ILC482 & 0.82 \\
\hline 9 & G3 & FLIP 09-305C & 2.41 & G8 & FLIP $88-85 \mathrm{C}$ & 0.95 & G3 & FLIP 09-305C & 0.79 \\
\hline \multirow[t]{4}{*}{10} & G12 & FLIP 09-387C & 2.39 & G2 & FLIP 09-430C & 0.94 & G4 & FLIP 09-396C & 0.77 \\
\hline & SE & & 0.31 & & & 0.12 & & & 0.17 \\
\hline & LSD5\% & & 0.89 & & & 0.34 & & & 0.49 \\
\hline & Mean (15 genotypes) & & 2.33 & & & 0.98 & & & 0.93 \\
\hline \multicolumn{10}{|c|}{ CIABN (2014-15) } \\
\hline \multicolumn{2}{|l|}{ Rank } & Genotype name & $\begin{array}{l}\text { Kabul } \\
\left(\mathrm{t} \mathrm{ha}^{-1}\right)\end{array}$ & GCode & Genotype name & \multicolumn{2}{|l|}{$\begin{array}{l}\text { Herat } \\
\left(\mathrm{t} \mathrm{ha}^{-1}\right)\end{array}$} & & \\
\hline 1 & G41 & ILC263 & 0.47 & G27 & FLIP 09-276C & \multicolumn{2}{|l|}{2.25} & & \\
\hline 2 & G23 & FLIP 09-237C & 0.36 & G19 & FLIP 09-194C & \multicolumn{2}{|l|}{2.11} & & \\
\hline 3 & G38 & FLIP 09-388C & 0.36 & G40 & FLIP 09-414C & \multicolumn{2}{|l|}{2.09} & & \\
\hline 4 & G35 & FLIP 09-362C & 0.34 & G8 & FLIP 09-16C & \multicolumn{2}{|l|}{1.84} & & \\
\hline 5 & G20 & FLIP 09-217C & 0.33 & G2 & FLIP 07-201C & \multicolumn{2}{|l|}{1.78} & & \\
\hline 6 & G26 & FLIP 09-248C & 0.33 & G32 & FLIP 09-328C & \multicolumn{2}{|l|}{1.75} & & \\
\hline 7 & G37 & FLIP 09-384C & 0.32 & G9 & FLIP 09-47C & \multicolumn{2}{|l|}{1.74} & & \\
\hline 8 & G10 & FLIP 09-55C & 0.32 & G33 & FLIP 09-334C & \multicolumn{2}{|l|}{1.71} & & \\
\hline 9 & G17 & FLIP 09-170C & 0.31 & $\mathrm{G} 21$ & FLIP 09-222C & \multicolumn{2}{|l|}{1.70} & & \\
\hline 10 & $\mathrm{G} 21$ & FLIP 09-222C & 0.31 & G39 & FLIP 09-399C & \multicolumn{2}{|l|}{1.67} & & \\
\hline & SE & & 0.06 & & & \multicolumn{2}{|l|}{0.11} & & \\
\hline & LSD5\% & & 0.16 & & & \multicolumn{2}{|l|}{0.32} & & \\
\hline & Mean (41 genotypes) & & 0.25 & & & \multicolumn{2}{|l|}{1.37} & & \\
\hline
\end{tabular}




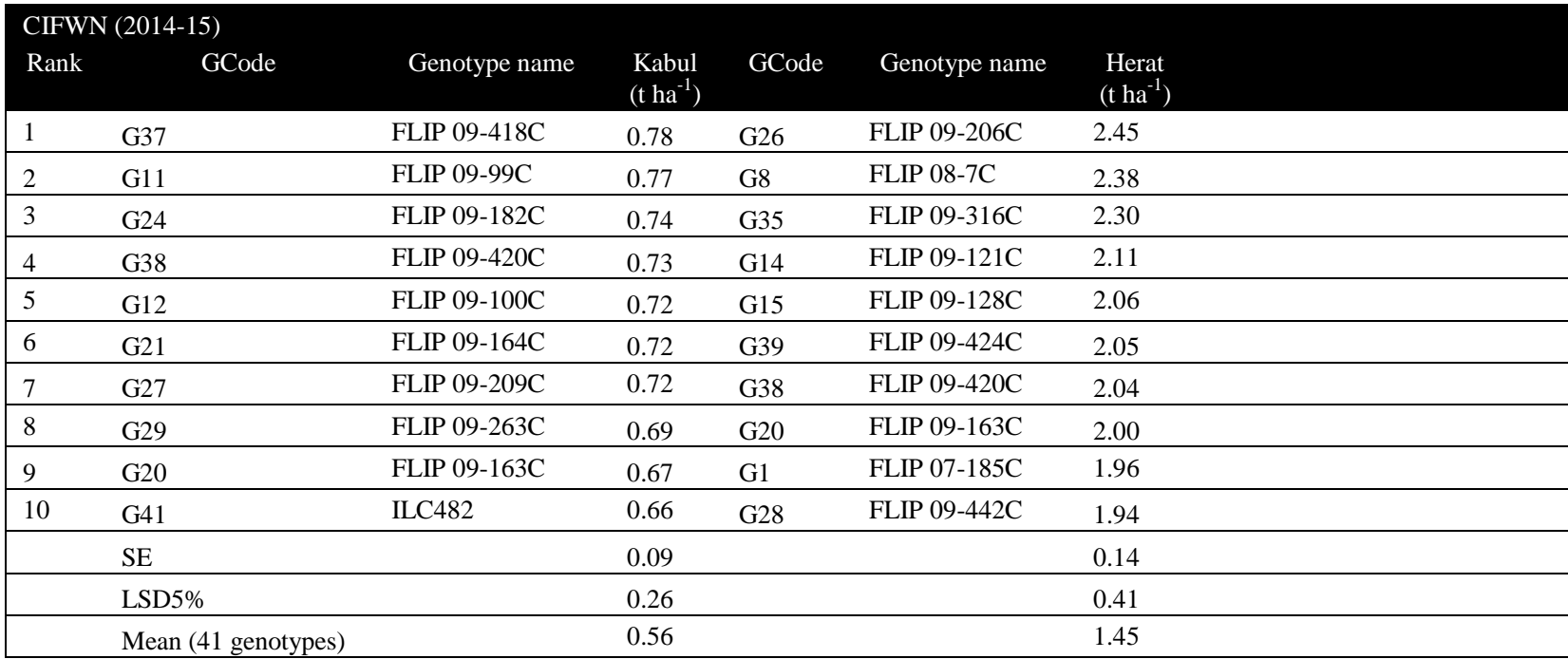

${ }^{\$}$ For CIEN-W trial, the mean yields are adjusted for lattice blocks. ${ }^{\circledR}$ GCode $=$ Genotype codes are G1...G41, where the same code over different trial-types or years for the same trial type generally stand for different genotypes. LC= Local check. SE $=$ standard error. LSD5\%= Least significant difference at 5\% level of significance. $\mathrm{CIEN}-\mathrm{W}=$ Chickpea International Elite Nursery Winter. CIABN $=$ Chickpea International Ascochyta Blight Nursery. CIFWN = Chickpea International Fusarium Wilt Nursery

\section{Conclusion}

This study presents the findings of three chickpea trials conducted in block designs with two or three replicated at multi-locations for two years (2014-15 and 2015-16) in Afghanistan. Out of 14 tested environments, genotypic differences were statistically significant $(\mathrm{P}<0.05)$ in ten environments. Genotype $\mathrm{x}$ location interactions were significant $(\mathrm{P}<0.01)$ in each of the two years for CIEN-W trial and during 2015 for CIABN and CIFWN trials. There was a strong genotype $\mathrm{x}$ year interaction of crossover type. For CIEN-W genetic materials, Kabul and Baghlan formed a mega-environment based on responses in 2015. The high yielding genotypes and also specifically adapted genotypes were G32 (ILC482) in Kabul (both years) and Baghlan (2015), G3 (FLIP 09-131C) in 2015 and G8 (FLIP 88-85C) in 2016 in Nangarhar and G7 (FLIP 09-441C) in 2016 in Baghlan. The high yielding genotypes from yield in 2015 were G41 (ILC263) in Kabul and G27 (FLIP 09-276C) in Herat from CIABN trials, and G37 (FLIP 09-418C) in Kabul and G26 (FLIP 09-206C) in Herat from the CIFWN trials. The identified genotypes from CIEN-W at the three locations and the other two trials in Herat may be used for up-scaling the production to support food security in Afghanistan as well as for generating new genotypes using crossing, selection and evaluation.

\section{Acknowledgements}

Authors thank the reviewers for their constructive comments and suggestions which substantially improved the presentation of an earlier version of the manuscript. Authors acknowledge the Department of Agriculture, Irrigation and Livestock (DAIL), Ministry of Agriculture, Irrigation and Livestock (MAIL), Afghanistan for providing research platform facilities, and thank the field technicians Mr. Nooralhaq Hakimi, 'Abdul Rahman Rahmni, Naween Safi, Mawya Masomi, Abdulhaq Farhang and Hedayet Safi for collecting the data from the trials presented. IFAD support for the project was duly acknowledged.

\section{Conflict of interest}

Authors declare that there is no conflict of interests arising from this study.

\section{References}

Atnaf M, Kidane S, Abadi S, Fisha Z (2013) GGE biplots to analyze soybean multi-environment yield trial data in north Western Ethiopia. Journal of Plant Breeding and Crop Science5: 245-254.

Atta BM, Shah TM (2009) Stability analysis of elite chickpea genotypes tested under diverse environments. Australian Journal of Crop Science 3:249-256.

Bakhsh A, Akhtar LH, Malik RS, Masood A, Iqbal SHM, Qureshi R (2011) Grain yield stability in chickpea (Cicer arietinum L.) across environments. Pakistan Journal of Botany 43: 2947-2951. 
Bozoglu H, Gulumser A (2000) Determination of GENOTYPE BY ENVIRONMENT interaction of some agronomic characteristics in dry bean. Turkish Journal of Agriculture and Forestry 24:211-222

Deb AC, Khaleque MA (2004) Study of genetic diversity of some of the yield and yield contributing characters in chickpea (Cicer arietinum L.). Journal of Science Foundation 2: 77-82.

DeLacy IH, Basford KE, Cooper M, Fox PN (1996a) Retrospective analysis of historical data sets from multienvironment trials- Theoretical development. In: Cooper M, Hammer GL (Eds): 'Plant Adaptation and Crop Improvement', CAB International: Wallingford, UK, Pp. 243-267.

DeLacy IH, Ratnasiri WGA, Mirzawan PDN (1996b) Retrospective analysis of historical data sets from multienvironment trials-Case studies. In: Cooper M, Hammer GL (Eds.) Plant Adaptation and Crop Improvement', CAB International: Wallingford, UK, Pp. 269-290.

Eberhart SA, Russell WA (1966) Stability parameters for comparing varieties. Crop Science 6: 36-40.

FAO (2014) FAOSTAT: ProdSTAT. Food and Agricultural Organization of the United Nations, Rome, Italy. http://faostat3.fao.org/download/Q/QC/E. Accessed on 17 September 2017.

FAOSTAT (2016). Food and Agriculture Organization of the United Nations. www.faostat.org. Accessed on 17 September 2017.

Farshadfar E, Hassan Z, Reza M (2011) Evaluation of phenotypic stability in chickpea genotypes using GGE-Biplot. Annals of Biological Research 2:282-292

Finlay KW, Wilkinson GN (1963) The analysis of adaptability in plant breeding programme. Australian Journal of Agricultural Research 14: 742-754.

Gauch HG, Zobel RW (1988) Predictive and postdictive success of statistical analyses of yield trials. Theoretical and Applied Genetics 76: 1-10.

ICARDA (2014). IFFVC Baseline Report, Community Livestock and Agriculture Program. International Center for Agricultural Research in the Dry Areas (ICARDA), Afghanistan Research Program. Kabul.

Imtiaz M, Malhotra RS, Singh M, Arslan S (2013) Identifying High Yielding, Stable Chickpea Genotypes for Spring Sowing:
Specific Adaptation to Locations and Sowing Seasons in the Mediterranean Region. Crop Science 53: 1472-1480.

International Crops Research Institute for Semi- Arid Tropics (2017) http://exploreit.icrisat.org/profile/Chickpea/232. Facts and figures. Accessed on 17 September 2017.

Kan A, Kaya M, Gurbuz A, Sanli A, Ozcan, Ciftci CY (2010) A study on genotype $\mathrm{x}$ environment interaction in chickpea cultivars (Cicer arietinum L.) grown in arid and semi-arid conditions. Scientific Research and Essays 5: 1164-1171.

Kempthorne O (1952) The Design and Analysis of Experiments. New York: John Wiley \& Sons.

Lin CS, Binns MR, Lefkovitch LP (1986) Stability analysis: Where do we stand? Crop Science 26: 894-900.

MAIL (2014) Statistical information. Ministry of Agriculture, Irrigation and Livestock, Kabul, https://mail.gov.af/en /page/3489/agricultural-prospect-reports. Accessed 17 on September 2017.

Malhotra RS, Singh M, Erskine W (2007) Genotype $\times$ environment interaction and identification of dualseason cultivars in chickpea. Euphytica 158: 119-127.

Mukamuhirwa F, Tusiime G and Mukankusi MC (2015) Genotype $\mathrm{x}$ Environment interactions for higher Iron and Zinc in selected bean varieties. Ambit Journal of Agriculture 2:16-39

Nahar SMN (1997) Genetic study of economically important characters and construction of selection index in sugarcane. Ph.D. Thesis submitted to the Rajshahi University, Bangladesh.

Negash AW (2015) Application of Mixed Model and Spatial Analysis Methods in Multi-Environmental and Agricultural Field Trials. School of Mathematics, Statistics and computer Science University of KwaZulu-Natal Petermaritzburg.

Pervin MA, Polash MFMB, Rahman SM, Deb AC (2007) Study of Genetic Variability and GXE Interaction of Some Quantitative Traits in Blackgram [Vigna mungo (L.) Hepper]. Journal of Biological Sciences 7: 169-175.

Singh KB, Bejiga G, Malhotra RS (1990) Associations of some characters with seed yield in chickpea collections. Euphytica 49:83-88.

Tavva S, Singh M, Rizvi J, Saharawat YS and Swain N (2017). Potential of introducing improved production practices in food legumes in increasing food security in Afghanistan. Scientia Agricola (in press). 
Tilahun G, Mekbib F, Fikre A, Eshete M (2015) Genotype x environment interaction and stability analysis for yield and yield related traits of Kabuli-type Chickpea in Ethiopia. Journal of Biotechnology 14:1564-1575.

VSN International (2015) The Guide to the Genstat Command Language (Release 18), Part 2 Statistics. VSN International, Hemel Hempstead, UK
Yan W (2011) GGE Biplot vs. AMMI Graphs for Genotype-byEnvironment Data Analysis. Journal of the Indian Society of Agricultural Statistics 65: 181-193.

Yan W, Hunt LA, Sheng Q, Szlavnics Z (2000) Cultivar evaluation and mega-environment investigation based on GGE biplot. Crop Science 40: 597-605. 